\title{
BENTENG VAN DEN BOSCH, NGAWI: Temuan Artefaktual Sebagai Cerminan Alat-alat Kebutuhan Sehari-hari
}

\author{
FORT VAN DEN BOSCH, NGAWI: \\ Findings Artefaktual For Reflection \\ Tools Everyday Needs
}

\author{
Muhammad Chawari \\ Balai Arkeologi Yogyakarta \\ mchawari@gmail.com
}

\begin{abstract}
Research in Fort Van den Bosch in Ngawi, East Java Province brings about data on aspects of the buildings and artifacts that accompany it. Regarding the artifacts a number of fragments of pottery, metal, ceramics, glass, animal bones, and shells have been found. They were objects of everyday appliances, except for bones and shells. Those artefacts could show the activities of the fort's inhabitants in the past.
\end{abstract}

Key words: Ngawi, Fortr, Van den Bosch, and Artefaktual.

\begin{abstract}
ABSTRAK
Penelitian di Benteng Van den Bosch di Kabupaten Ngawi, Provinsi Jawa Timur menghasilkan data baik tentang aspek bangunan benteng maupun artefak yang menyertainya. Khusus mengenai temuan artefak, telah ditemukan sejumlah fragmen gerabah, fragmen logam, fragmen keramik asing, fragmen kaca, fragmen tulang, dan fragmen kerang. Fragmen-fragmen tersebut berasal dari benda-benda peralatan sehari-hari, kecuali fragmen tulang dan fragmen kerang. Dengan mempelajari temuan artefaktual diharapkan gambaran tentang aktivitas para penghuni benteng di masa lampau dapat diketahui.
\end{abstract}

Kata kunci: Ngawi, Benteng, Van den Bosch, dan Artefaktual.

Tanggal masuk : 17 Mei 2016

Tanggal diterima : 31 Oktober 2016 


\section{PENDAHULUAN}

Secara administratif Benteng Van den Bosch terletak di Kelurahan Pelem, Kecamatan Ngawi Kota, Kabupaten Ngawi, Provinsi Jawa Timur. Ngawi merupakan salah satu kabupaten di Provinsi Jawa Timur dan dianggap penting pada jamannya. Pentingnya Ngawi di masa lalu dapat diketahui dengan adanya tinggalan fisik yang berupa bangunan, terutama bangunan tinggalan Belanda. Salah satunya adalah Benteng Van den Bosch. Benteng ini sudah pernah ditulis sebagai skripsi di Jurusan Arkeologi, Fakultas Ilmu Budaya, Universitas lokal. Benteng ini dilengkapi beberapa komponen pendukung yaitu: bangunan pengintaian, parit keliling, tanggul keliling, jembatan angkat, dan bastion. Selanjutnya disebutkan bahwa benteng ini berada di tepi pertemuan Sungai Bengawan Solo dan Sungai Madiun (Sumarno, 1990: 119 - 121).

Selanjutnya pada tahun 1996 Balai Arkeologi Yogyakarta pernah mengadakan penelitian yang dilakukan melalui survei yaitu Sarana Pertahanan Kolonial di Kabupaten Ngawi, Kabupaten Bangkalan, dan Kabupaten Situbondo, Provinsi Jawa Timur (Tahap IV). Dalam penelitian

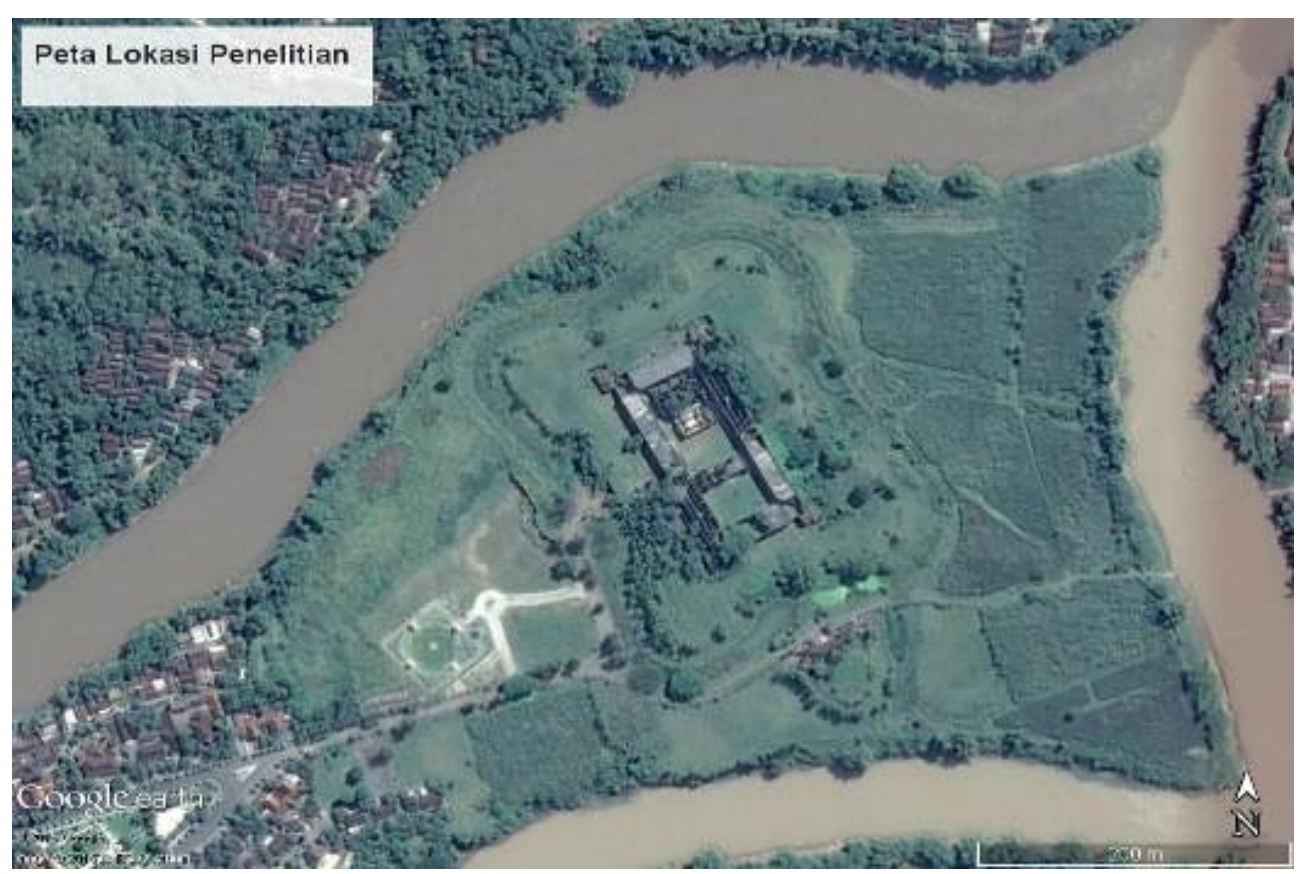

Sumber. Google Earth

Gambar 1. Peta keberadaan Benteng Van den Bosch terhadap Sungai Bengawan Solo dan Sungai Madiun

Gadjah Mada oleh Aris Sumarno tahun 1990 dengan judul "Benteng Pendem Belanda Abad XIX Di Kabupaten Ngawi, Tinjauan Terhadap Arsitektur dan Pemilihan Lokasi". Disebutkan dalam skripsi tersebut bahwa benteng ini tidak seluruhnya berarsitektur Eropa, tetapi bercampur dengan arsitektur tersebut tidak hanya benteng pertahanan Belanda saja yang didata, akan tetapi juga kompleks makam Belanda. Secara keseluruhan benteng Van den Bosch berdenah empat persegi panjang. Terdapat pintu masuk utama yang terletak di sisi barat daya. Benteng ini dikelilingi oleh tanggul buatan dari 
tanah yang lebih tinggi dari pada benteng itu sendiri. Di luar tanggul buatan tersebut terdapat parit keliling yang dilengkapi dengan satu jembatan angkat yang terdapat di depan pintu masuk utama (Abbas, 1996/1997: 5).

Benteng Van den Bosch juga pernah menjadi salah satu objek dalam pembuatan tesis bersama beberapa benteng lain di Jawa oleh Novida Abbas pada tahun 2001 dengan judul "Dutch Forts of Java, $A$ Locational Study". Disebutkan bahwa benteng ini terletak sekitar 2,5 km timur laut kota Ngawi. Benteng ini dibangun pada tahun 1839 di atas tanah seluas $12 \mathrm{ha}$, setelah Perang Diponegoro berakhir. Belanda membangun benteng Van den Bosch di sudut timur laut kota untuk mengawasi lalu lintas air yang melewati Sungai Madiun dan Sungai Bengawan Solo (Abbas: 2001: 55).

Benteng Van den Bosch yang didirikan delapan tahun setelah perang Diponegoro berakhir dibangun untuk memenuhi kebutuhan Belanda yang antara lain berkaitan dengan masalah ekonomi. Setelah kemerdekaan, benteng ini dipakai oleh Bataliyon ARMED 12 KOSTRAD Ngawi, dan sejak tahun 2011 diserahkan kepada Pemerintah Daerah Kabupaten Ngawi. Berarti sejak itu penelitian arkeologis dapat dilakukan dengan lebih seksama dan terbuka. Oleh karena bangunan ini masih berdiri (meskipun beberapa bagian telah runtuh), bentuk dan arsitekturnya masih bisa diketahui. Sementara tinggalan yang ada di bawah permukaan tanah, sebagai pendukung utama tinggalan yang ada di permukaan tanah perlu diungkap. Sehubungan dengan hal tersebut maka penelitian ini berusaha untuk menjawab pertanyaan: seperti apa tinggalan yang bersifat non-monumental atau artefaktual yang ada di situs ini.

Penelitian ini bertujuan untuk mengetahui dan melihat gambaran awal tentang kehidupan para penghuni benteng Van den Bosch.

\section{METODE PENELITIAN}

Survei dan ekskavasi dilakukan dalam penelitian ini untuk mendapatkan data fisik yang bersifat monumental dan non-monumental. Data monumental berupa bangunan beserta unsur-unsurnya, sementara data non-monumental terdiri atas berbagai tinggalan benda yang berupa sisa-sisa aktivitas masa lampau. Kedua data tersebut penting untuk mengetahui aktivitas penghuni benteng di masa lampau. Penelitian ini bersifat deskriptif dengan penalaran induktif. Metode ini dimaksudkan untuk memberikan gambaran umum terhadap data arkeologi yang diperoleh.

\section{HASIL PENELITIAN}

\section{a. Survei Lapangan}

Seluruh tinggalan yang disurvei secara administratif terletak di Desa Pelem, Kecamatan Ngawi, dan terdiri atas:

\section{Bangunan Societeit \\ Keberadaan objek ini} diketahui berdasarkan peta lama sekitar awal abad 20. Dewasa ini bangunan tersebut tersisa fondasi saja. Berdasarkan keletakannya, fondasi ini terletak di luar benteng sebelah timur dan mendekati pertemuan dua sungai, yaitu Sungai Bengawan Solo dan Sungai Madiun.

\section{Gorong-gorong Air \\ Objek ini terletak di luar benteng sebelah timur, persisnya ada di sebelah barat bangunan}


societeit. Dengan demikian jarak dengan benteng lebih dekat. Dewasa ini gorong-gorong tersebut sudah tidak berfungsi lagi sebagaimana mestinya. Bagian atas gorong-gorong dahulu berfungsi sebagai jalan.

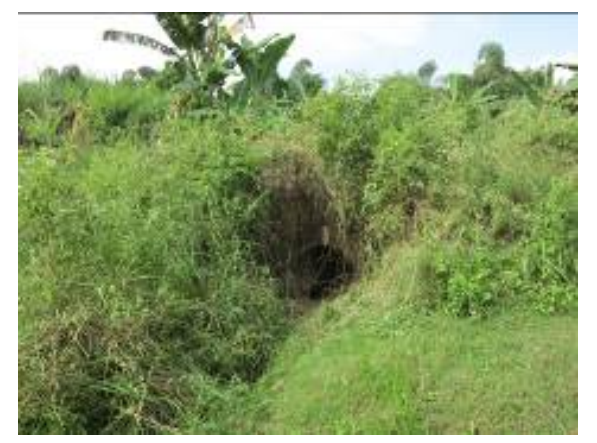

Gambar 2. Foto gorong-gorong air yang terletak antara benteng dan societeit

Sumber: Balai Arkeologi D.I. Yogyakarta

\section{Saluran Pembuangan Air}

Saluran ini terletak di sebelah timur benteng. Letaknya persis di sisi timur parit keliling benteng. Objek ini dibuat dengan menggunakan bata merah yang disusun dengan memakai lepa. Pada bagian atas berbentuk lengkung dan sekarang sebagian batanya telah hilang (jatuh ke bawah). Kondisi ini disebabkan pada bagian samping objek tumbuh pohon yang cukup besar. Akar pohon ini merupakan salah satu penyebab rusaknya saluran ini. Saluran ini pada kedua sisinya (luar dan dalam) penuh dengan tanaman liar. Sementara pada sisi luar (sebelah timur) tanahnya lebih tinggi, sehingga air tidak bisa keluar. Inilah yang menyebabkan saluran ini tidak dapat berfungsi dengan baik.

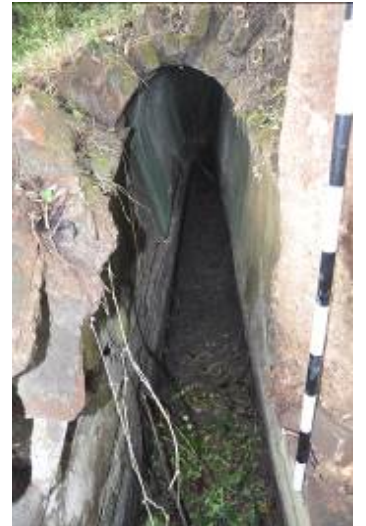

Gambar 3. Foto saluran pembuangan air ke luar benteng

Sumber: Balai Arkeologi D.I. Yogyakarta

\section{Kompleks Makam Belanda}

Kompleks makam ini diberi batas berupa pagar keliling dan di bagian depan terdapat gapura. Pada ambang atas gapura terdapat tulisan MEMENTOMORI dan angka tahun 1885. Mementomori berarti peringatan. Kompleks makam Belanda ini berada di sebelah barat daya benteng dan sekarang menjadi kompleks makam umum dan berada di bawah pengelolaan Dinas Kebersihan Kabupaten Ngawi. Sebagai kompleks makam Belanda, situs tersebut dewasa ini sering didatangi orang-orang Belanda. Pemakaman ini difungsikan antara tahun 1878 - tahun 1929 berdasarkan angka tahun yang tertera pada makam-makam di situs tersebut.

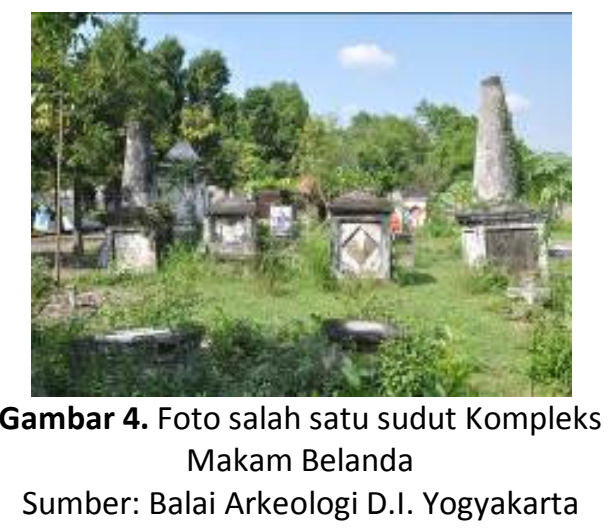


5. Bangunan Rumah Tinggal

Bangunan rumah bergaya indis dapat ditemukan di bagian depan benteng, yaitu di sekitar pintu gerbang penjagaan. Bangunan tersebut dewasa ini masih dimanfaatkan, namun ada beberapa yang tidak dihuni, bahkan ada satu bangunan yang akan dijual. Hal ini diketahui karena adanya tulisan yang ditempel di bagian depan bangunan. Beberapa bangunan yang sekarang masih berfungsi antara lain untuk mess milik YON ARMED 12 KOSTRAD, rumah dinas komandan ARMED 12, rumah dinas anggota ARMED 12, dan ada pula yang dimiliki perseorangan. Secara umum kondisi seluruh bangunan dalam keadaan utuh.

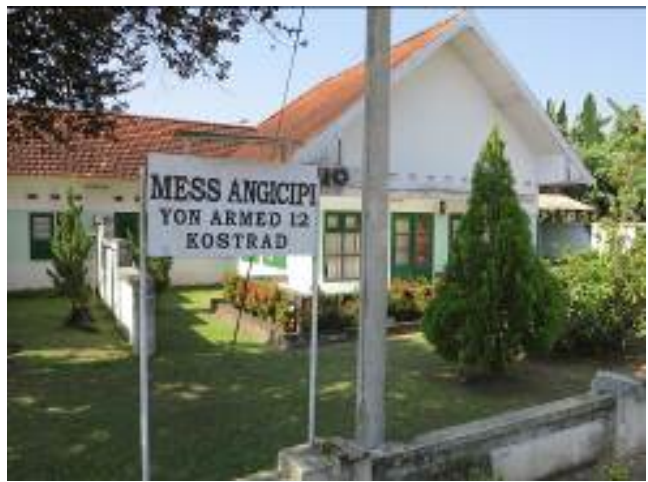

Gambar 5. Foto salah satu bangunan milik YON ARMED 12 KOSTRAD

Sumber: Balai Arkeologi D.I. Yogyakarta

\section{b. Ekskavasi}

Selain survei dilakukan pula ekskavasi. Telah dibuka kotak gali sebanyak 13, yaitu:

\section{Kotak P1}

Kotak P1 terletak di sebelah barat pintu gerbang benteng, untuk

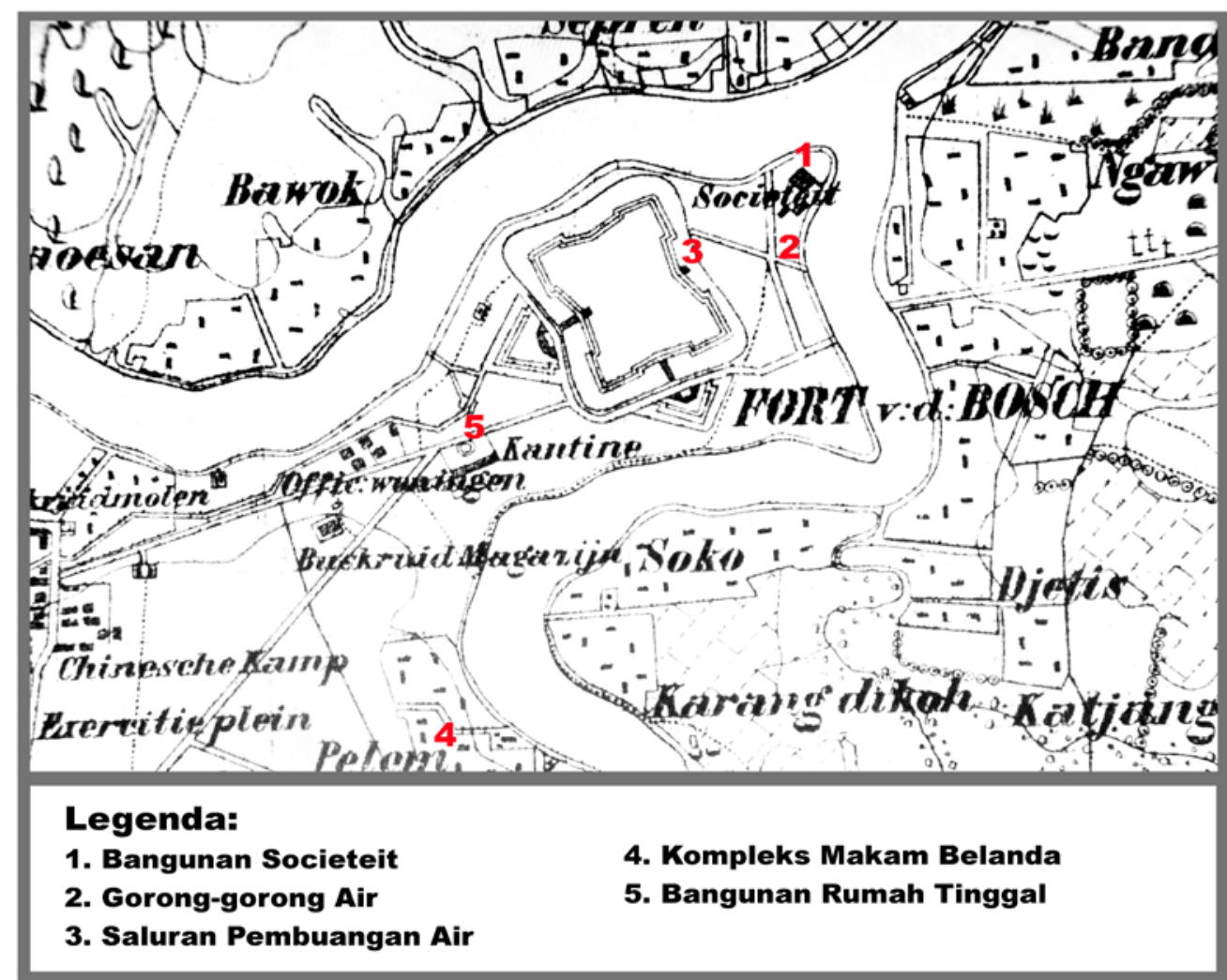

Gambar 6. Peta keletakan beberapa tinggalan hasil survei Sumber: Peta asli dengan modifikasi oleh Balai Arkeologi D.I. Yogyakarta 
mengetahui bentuk dan denah struktur bata yang masih kelihatan di permukaan tanah. Secara khusus kotak ini digali untuk mengetahui posisi jembatan angkat yang ada di depan pintu masuk benteng. Mulai kedalaman $30 \mathrm{~cm}$ terlihat struktur bata. Struktur tersebut membagi kotak P1 dalam dua bagian yaitu bagian selatan dan utara. Hingga kedalaman $60 \mathrm{~cm}$ struktur bata tersebut berjumlah 8 lapis bata. Susunan bata tersebut ke bawah semakin melebar. Temuan lainnya adalah fragmen keramik (baik Cina maupun Eropa), fragmen kaca, fragmen gerabah, fragmen logam, fragmen genteng, dan satu benda (berbahan besi serta cangkang kerang) yang tidak bisa diidentifikasi jenisnya.

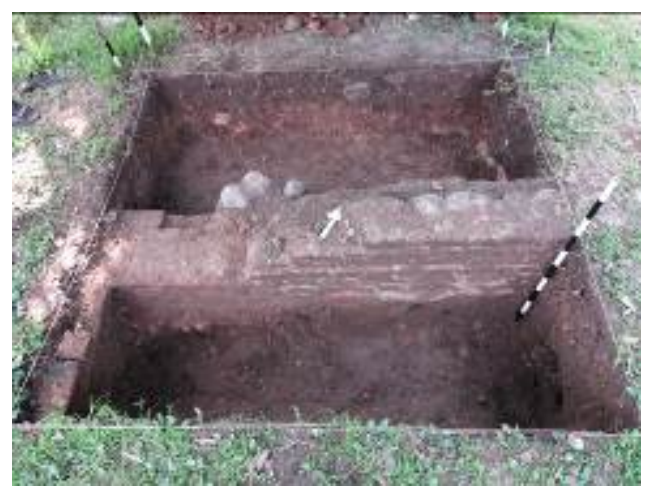

Gambar 6. Foto akhir penggalian Kotak P1 Sumber: Balai Arkeologi D.I. Yogyakarta

\section{Kotak P2}

Kotak P2 berada di sebelah selatan kotak P1 dalam posisi berhimpit. Kotak ini dibuka untuk merunut struktur bata yang telah ditemukan di kotak P1. Kotak ini secara khusus diarahkan pula untuk mengetahui keletakan jembatan angkat. Struktur bata yang ada di kotak ini berada di sisi selatan dan berjumlah 9 lapis bata. Temuan serta yang lain adalah fragmen keramik, fragmen kaca, fragmen gerabah, fragmen logam, dan fragmen genteng.

\section{Kotak P3}

Letak kotak P3 di sebelah barat dinding pintu gerbang. Kotak P3 dibuka dengan tujuan untuk mengetahui struktur landasan jembatan angkat. Mulai kedalaman sekitar $50 \mathrm{~cm}$ terlihat adanya struktur bata yang memanjang sepanjang kotak. Secara nyata terlihat bahwa struktur bata bagian timur tersusun rapi sedangkan pada bagian barat dalam kondisi tidak teratur. Struktur bata ini terdiri atas satu lapis bata. Temuan lain adalah fragmen keramik, fragmen botol, fragmen gerabah, fragmen logam, serta fragmen tulang binatang.

\section{Kotak P4}

Kotak P4 terletak di sebelah barat dan berhimpit dengan kotak P3. Kotak P4 dibuka dengan tujuan untuk mencari struktur landasan jembatan angkat, juga untuk merunut struktur bata yang telah nampak pada kotak P3. Struktur bata mulai ditemukan pada kedalaman $54 \mathrm{~cm}$ dan berjumlah satu lapis bata. Di bawahnya terdapat lapisan bata lain dengan susunan tidak beraturan. Adapun temuan lepas terdiri atas fragmen kaca, fragmen gerabah, dan fragmen logam.

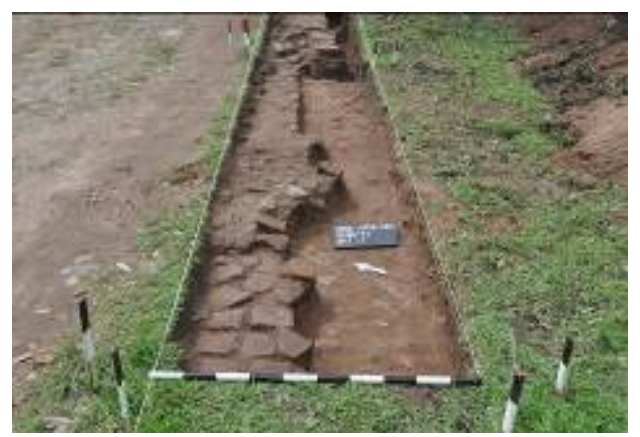

Gambar 7. Foto akhir penggalian Kotak P4 Sumber: Balai Arkeologi D.I. Yogyakarta

\section{Kotak P5}

Kotak P5 berada di sebelah barat kotak P4 dan bertujuan untuk 
mencari struktur landasan jembatan angkat, juga untuk merunut struktur bata yang telah nampak pada kotak P3 dan P4. Kotak ini temuannya sama dengan temuan di kotak P4 yaitu berupa struktur bata satu lapis. Sementara temuan artefaktualnya berupa fragmen kaca dan fragmen logam.

\section{Kotak P6}

Posisi kotak P6 berada persis di sebelah barat dan berimpit dengan kotak P5 serta dengan dinding pintu gerbang benteng. Kotak P6 dibuka dengan tujuan untuk mencari struktur landasan jembatan angkat, dan sekaligus untuk merunut struktur bata yang telah kelihatan pada kotak P3, P4, dan P5. Temuannya berupa struktur bata sebanyak satu lapis dan temuan artefaktual berupa fragmen logam.

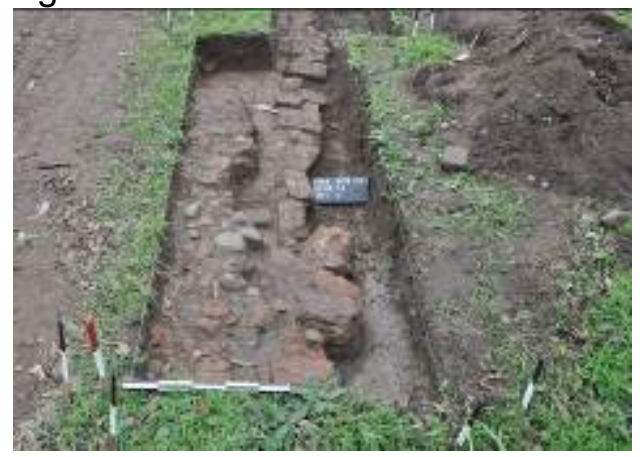

Gambar 8. Foto akhir penggalian Kotak P6 Sumber: Balai Arkeologi D.I. Yogyakarta

\section{Kotak P7}

Kotak P7 berada di sebelah barat dinding gerbang. Kotak P7 dibuka dengan tujuan untuk mencari struktur landasan jembatan angkat dan melihat lebih jauh profil struktur bata yang terdapat di permukaan. Pada permukaan kotak sudah terlihat struktur bata yang terdapat pada sisi barat kotak. Struktur tersebut berlanjut terus ke bawah. Di bagian atas struktur tersebut tidak menggunakan lepa, akan tetapi di bagian bawah dilepa. Kemudian pada kedalaman antara 80 s.d. 100 $\mathrm{cm}$ ditemukan gorong-gorong air dengan ketebalan $10 \mathrm{~cm}$ dan diameter $90 \mathrm{~cm}$. Selanjutnya temuan artefaktual berupa fragmen keramik, fragmen gerabah, fragmen logam (paku, pengait, tutup kaleng, besi, dan beberapa benda logam yang tidak jelas bentuknya).

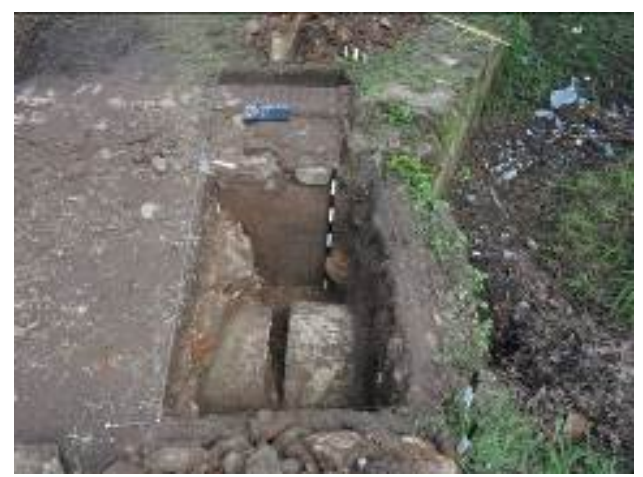

Gambar 9. Foto landasan jembatan angkat sisi barat pada kotak P7

Sumber: Balai Arkeologi D.I. Yogyakarta

\section{Kotak T1}

Kotak T1 terletak pada tanggul sisi timur atau bagian belakang benteng. Pembukaan kotak T1 bertujuan untuk mengetahui bentuk sesungguhnya salah satu struktur bata yang berada di tanggul ini. Struktur bata yang dimaksud diduga merupakan fondasi dari sebuah bangunan (pagar?). Informasi ini didasarkan atas peta Belanda yang ada. Disampaikan pula bahwa di sepanjang tanggul terdapat 10 fondasi sejenis. Salah satu dari fondasi tersebut dibuka dan diberi nama dengan kotak T1. Dalam penggalian, fondasi bata ditempatkan pada bagian tengah kotak. Setelah menggali hingga kedalaman antara $40-50 \mathrm{~cm}$ diketahui bahwa struktur ini berukuran $45 \times 46 \mathrm{~cm}$ dengan ketebalan $32 \mathrm{~cm}$. Artefak yang ditemukan berupa fragmen keramik, fragmen gerabah, beberapa artefak 
berjenis logam seperti paku, mur baut, kawat, dan selongsong peluru.

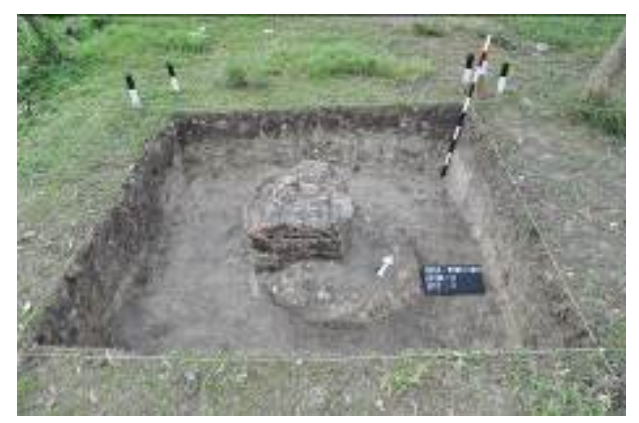

Gambar 10. Foto akhir penggalian kotak T1 Sumber: Balai Arkeologi D.I. Yogyakarta

\section{Kotak D1}

Kotak D.1 terletak di dalam benteng yaitu di depan gudang amunisi dan penjara yang terletak di pojok barat daya benteng. Pembukaan kotak ini adalah untuk mencari artefak yang terkait dengan gudang amunisi khususnya dan artefak benteng pada umumnya. Temuan monumentalnya berupa struktur bata satu deret yang membujur dengan arah barat-timur. Sedangkan temuan artefaktualnya berupa fragmen gerabah, fragmen keramik, fragmen kaca, fragmen logam, fragmen genteng, fragmen tulang, dan fragmen besi (paku), selongsong peluru, dan 1 temuan yang belum diketahui bentuknya.

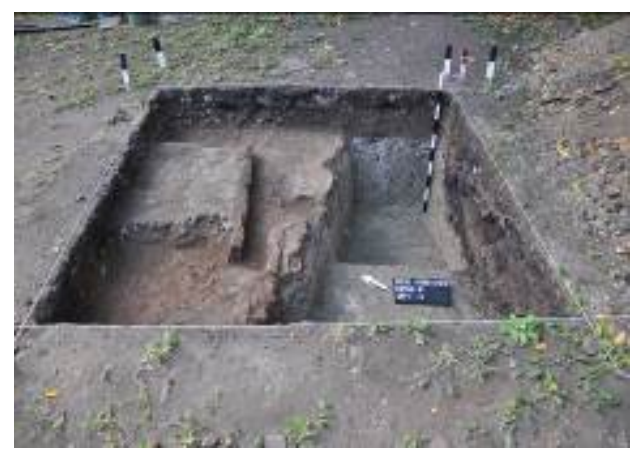

Gambar 11. Foto akhir penggalian kotak D1 Sumber: Balai Arkeologi D.I. Yogyakarta

\section{Kotak D2}

Kotak D2 ini juga terletak di dalam benteng, tepatnya di depan gedung sisi timur. Kotak ini digali untuk mencari artefak yang ada di depan gedung, sebab gedung ini diperkirakan sebagai tempat makan. Pada permukaan tanah sebelum digali ditemukan 2 tegel polos berwarna kuning. Secara umum temuannya berupa fragmen gerabah, fragmen keramik, fragmen kaca, paku, dan fragmen tulang.

\section{Kotak L1}

Kotak L1 terletak di depan pintu gerbang sisi timur benteng, tepatnya di sisi kiri gerbang. Alasannya untuk mencari artefak di sekitar luar benteng. Sampai kedalaman $20 \mathrm{~cm}$ temuan yang ada berupa fragmen keramik, fragmen kaca, fragmen gerabah, logam (berupa selongsong peluru, slot pintu, mur baut, paku, dan pengait), serta fragmen tulang binatang. Kemudian pada kedalaman $60 \mathrm{~cm}$ menemukan tegel polos berwarna kuning dan bertuliskan "ALFRED REGOUT $80 \quad$ MAASTRICHT HOLLAND"

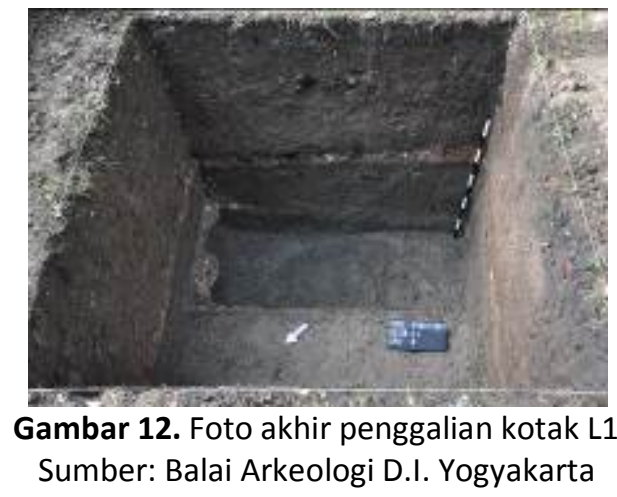

\section{Kotak JP1}

Kotak JP1 terletak pada tanggul parit sisi luar sebelah timur. Kotak ini dibuka dengan tujuan untuk melihat dan mengetahui gejala jalan patroli serta sejauhmana 
perubahannya hingga saat ini. Secara umum temuan di dalam kotak ini berupa fragmen gerabah, fragmen keramik, dan fragmen tulang.

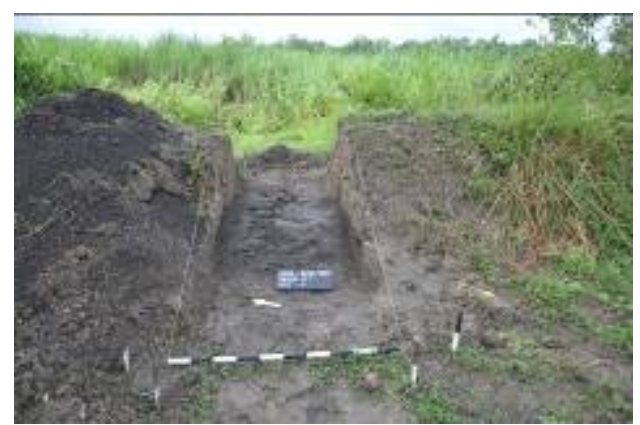

Gambar 13. Foto akhir penggalian kotak JP1 Sumber: Balai Arkeologi D.I. Yogyakarta

\section{Kotak JP2}

Kotak JP2 berada di sebelah utara kotak JP1 berjarak 15 meter. Kotak ini dibuka dengan tujuan untuk melihat dan mengetahui gejala jalan patroli. Sampai kedalaman $60 \mathrm{~cm}$ gejala pemadatan tanah untuk jalan patroli seperti yang diperkirakan sebelumnya tidak ada. Dengan keadaan yang demikian diartikan bahwa gejala jalan patroli tidak ada, kecuali hanya tanah yang ditinggikan yang kemudian difungsikan sebagai jalan untuk mengelilingi benteng. Temuan yang ada di kotak ini bersifat fragmentaris yaitu fragmen keramik, fragmen gerabah, dan fragmen kaca.

\section{RAGAM DAN JENIS TEMUAN}

Untuk melihat dan mengetahui temuan hasil ekskavasi di Benteng Van den Bosch dan sekitarnya dapat dipilah menjadi 2 kelompok.

\section{a. Temuan Monumental}

Berdasarkan atas alasan pembukaan kotak gali dapat diketahui bahwa dari 13 kotak gali yang dibuka, 10 di antaranya bertujuan untuk mendapatkan data monumental. Di samping data monumental juga tidak dikesampingkan data nonmonumental atau data artefaktual. Ke-10 kotak gali tersebut adalah kotak P1 s.d. kotak P7, kotak T1, kotak JP1, dan kotak JP2. Di bawah ini adalah hasil yang diperoleh dari ke-10 kotak gali yaitu:

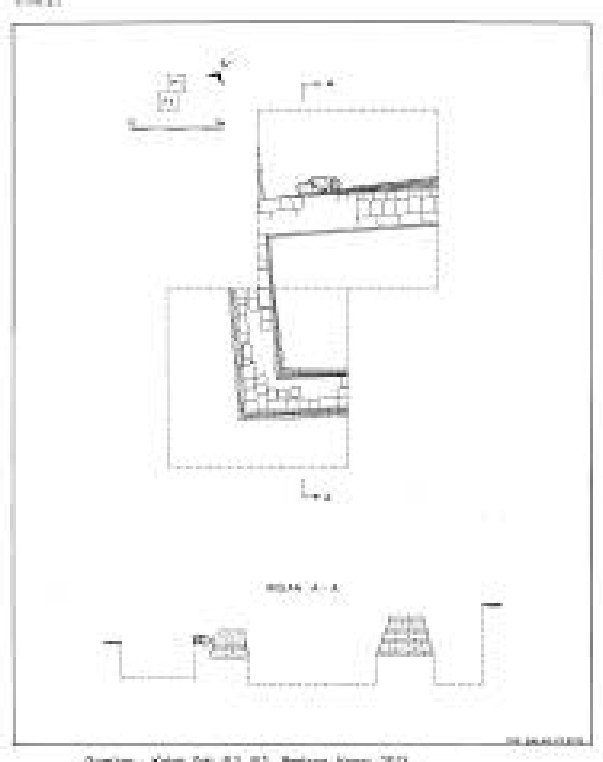

Gambar 14. Denah struktur bata bekas pos penjagaan

Sumber: Balai Arkeologi D.I. Yogyakarta

Hasil dari kotak P1 berupa struktur bata yang merupakan sebuah fondasi bangunan dan memiliki bentuk persegi panjang yang berorientasi barat-timur berukuran $250 \mathrm{~cm} \quad x \quad 500 \mathrm{~cm}$. Struktur tersebut memiliki bentuk seperti piramida terpenggal, pada bagian atas dengan penampang lebih kecil dari pada penampang bagian bawah. Bentuk struktur yang demikian dimungkinkan merupakan sebuah pondasi bangunan. Berdasarkan informasi dari Sertu Bambang Suwito (salah satu anggota ARMED 12) dikatakan bahwa struktur tersebut dahulu merupakan bangunan pos 
penjagaan. Umur bangunan tersebut kemungkinan lebih muda dari pada umur benteng. Hal ini berdasarkan ukuran bata yang digunakan dalam struktur bangunan tersebut yang lebih kecil dibandingkan dengan bata yang menjadi isian dalam tanah urug.

Hasil yang diperoleh dari kotak P2 adalah struktur bata yang merupakan kelanjutan dari kotak P1. Hasil dari kotak P3 adalah struktur bata satu lapis yang berorientasi barat-timur. Struktur tersebut kemungkinan merupakan lapisan yang digunakan sebagai pengerasan jalan seperti struktur bata yang masih kelihatan di permukaan tanah. Struktur ini juga berorientasi barattimur yang menjadi akses jalan masuk ke benteng.

Hasil dari kotak P4 sama dengan hasil kotak P3 yaitu struktur bata satu lapis yang di bawahnya dipadatkan dengan pecahan bata. Lapisan ini merupakan jalan masuk ke benteng. Hasil dari kotak P5 sama dengan kotak P3 dan P4, berupa struktur bata satu lapis yang di bawahnya dipadatkan dengan pecahan bata. Lapisan ini merupakan jalan sebagai akses dari dan ke benteng.

Berikutnya adalah hasil yang diperoleh dari kotak P6. Hasil dari kotak ini tidak sesuai dengan tujuan awal yaitu mencari struktur landasan jembatan angkat. Penggalian pada kotak P6 ini menemukan struktur bata dan batu sebagai perkerasan tanah. Kotak P7 memberikan hasil yang sesuai dengan harapan. Kotak P7 menunjukkan adanya struktur bata yang sudah terlihat sejak awal tetapi tidak menggunakan lepa, dan berlanjut terus ke bawah dan berlepa. Temuan ini diduga kuat merupakan struktur landasan jembatan angkat benteng. Hal tersebut didukung dengan profil struktur bata yang memiliki dan menggunakan "takikan". Temuan lain pada kotak P7 adalah tanah urug yang digunakan untuk menimbun gorong-gorong. Tanah urug ini ditemukan di sebelah timur struktur. Hal tersebut menimbulkan dugaan bahwa gorong-gorong tersebut merupakan tambahan baru. Hal ini dibuktikan ditemukannya berbagai macam pecahan material yang terdiri dari batu berukuran kecil hingga sedang, pecahan tegel, pecahan batu putih, dan pecahan bata di sekitar gorong-gorong tersebut.

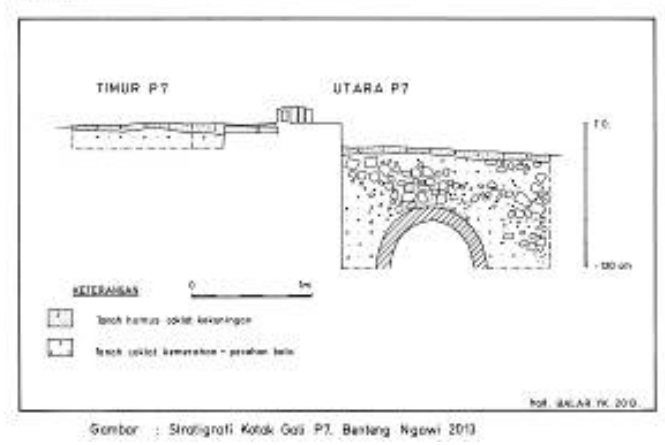

Gambar 15. Posisi gorong-gorong terhadap keletakan bekas jembatan angkat yang berada di bagian atas gorong-gorong

Sumber: Balai Arkeologi D.I. Yogyakarta

Kotak selanjutnya adalah T1. Kotak ini menghasilkan temuan berupa struktur bata yang terletak di atas tanggul dan berorientasi utaraselatan dengan posisi berderet satu baris. Dengan kondisi yang demikian diperkirakan bahwa temuan ini diduga merupakan fondasi pagar pembatas benteng.

Berikutnya adalah kotak JP1 dan JP2. Kedua kotak tersebut dibuka dengan tujuan untuk mencari jejak jalan patroli. Tujuan tersebut tidak seluruhnya tercapai karena jalan patroli yang dimaksud "hanya" berupa tanah yang ditinggikan. Dengan demikian dapat diartikan bahwa yang dimaksud dengan jalan 
patroli adalah tanah yang lebih tinggi dari permukaan tanah sekitarnya, dan kemudian difungsikan sebagai jalan untuk patroli para penjaga keamanan dalam mengelilingi benteng.

\section{b. Temuan Non-Monumental}

Kotak D1 dibuka dengan tujuan untuk mencari artefak yang terkait dengan keberadaan gudang amunisi. Tujuan dari penggalian kotak ini belum sepenuhnya tercapai, sebab temuan peluru ataupun bahan amunisi tidak terlalu banyak. Artefak yang ditemukan dari kotak ini berupa fragmen genteng, fragmen gerabah, fragmen keramik, fragmen kaca, fragmen logam (selongsong peluru, paku, engsel pintu, mur-baut, kancing, tutup kaleng), dan tulang.

Kotak D2 memperlihatkan temuan artefaktual berupa kebutuhan sehari-hari yang terdiri atas fragmen gerabah, fragmen keramik (sekring), fragmen kaca, fragmen logam (paku dan pengait), dan tulang.

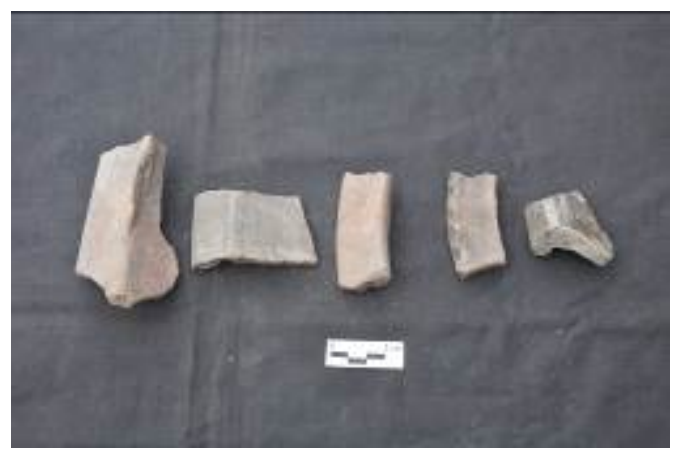

Gambar 16. Foto beberapa bentuk gerabah Sumber: Balai Arkeologi D.I. Yogyakarta

Demikian pula dengan kotak L1, artefak yang ditemukan berupa kebutuhan sehari-hari. Hal menarik pada kotak ini adalah dengan ditemukannya unsur bangunan yang berupa tegel. Tegel ini berwarna kuning dan bertuliskan "ALFRED REGOUT 80 MAASTRICHT- MADE
IN HOLLAND". ALFRED REGOUT 80 MAASTRICHT adalah pabrik porselin dan gerabah yang terletak di kota Maastricht (Belanda) dan berproduksi pada sekitar tahun 1835. Pabrik ini memproduksi barang-barang peralatan rumah tangga yang di dalamnya termasuk bahan bangunan yang berupa ubin (https://nl.wikipedia.org/wiki/Maastric hts).

Penelitian ini berhasil menemukan temuan artefaktual sejumlah 722 fragmen. Temuan tersebut dapat dikelompokkan menjadi 2 yaitu unsur bangunan monumental dan non-monumental. Unsur bangunan terdiri atas fragmen genteng (14 fragmen), tegel (1), dan gorong-gorong (1). Jenis-jenis artefak terdiri atas (diurutkan sesuai dengan jumlah): gerabah (233 fragmen), logam (189 fragmen), keramik (129 fragmen), kaca (65 fragmen), tulang (56 fragmen), unidentified (UI) (33 fragmen), dan kerang (1 fragmen).

Di bawah ini akan dipaparkan tentang masing-masing jenis temuan sesuai dengan jumlah. Temuan terbanyak adalah fragmen gerabah sebanyak 233 fragmen. Secara umum fragmen gerabah yang ditemukan merupakan gerabah polos, namun ada beberapa fragmen yang berhias. Secara kualitas dapat dikatakan bahwa seluruh temuan gerabah yang ada merupakan gerabah yang dapat digolongkan sebagai "biasa", bukan gerabah halus. Berdasarkan atas hasil dari analisis tersebut diketahui bahwa fragmen gerabah dengan jumlah 233 keping dapat dikelompokkan menjadi 2, yaitu wadah dan nonwadah. Kelompok wadah terdiri atas 12 jenis, yaitu: kendil, pengaron, kuali, genuk, padasan, kelenting, jun, kekep, kendi, gentong, keren, dan mangkuk. Adapun kelompok 
non-wadah terdiri atas 4 jenis, yaitu: figurin, gacuk, alat upam (?) atau gacuk besar, dan manik-manik. Khusus untuk figurin diperkirakan merupakan bagian dari hiasan yg berukuran tinggi $3,5 \mathrm{~cm}$, panjang 5,2 $\mathrm{cm}$, dan lebar $4 \mathrm{~cm}$. Selain itu terdapat fragmen gerabah berhias (3 keping), yaitu fr. genuk berhias motif sisik ikan; fr. padasan berhias motif kelopak mata; dan fr. pengaron berhias motif rantai.

Urutan kedua adalah logam sebanyak 189 fragmen. Temuan logam terdiri atas beberapa jenis, yaitu paku (106 fragmen), mur-baut (17 fragmen), fragmen besi (13 fragmen), fragmen lempeng (10 fragmen), pengait (8 fragmen), fragmen kawat berduri (8 fragmen), selongsong peluru (6 fragmen), peniti dan kancing (6 fragmen), fragmen engsel pintu (3 fragmen), fragmen slot pintu, fragmen jeruji, tutup kaleng, dan kunci (masingmasing 2 fgamen), mata uang, timang ikat pinggang, emblem, dan ring (masing-masing 1 fragmen). Temuan paku, mur-baut, dan fragmen besi terlihat sangat dominan.

Berikutnya adalah temuan keramik sebanyak 129 fragmen. Fragmen keramik asing yang ditemukan di benteng ini kebanyakan fragmen keramik Eropa (Belanda?) dan sisanya merupakan fragmen keramik Cina. Khusus untuk fragmen keramik Eropa salah satunya diketahui karena adanya tulisan latin dan Jawa Baru. Tulisan latinnya berbunyi ....trus Regout.....MAASTRICHT MADE IN HOLLAND. Sedangkan tulisan Jawa Baru kurang lebih terbaca Pe.....lu.....ké.....prik. Sementara itu fragmen keramik Cina yang ditemukan pada umumnya berasal dari Dinasti Qing. Secara keseluruhan Dinasti Qing ini meliputi kurun waktu yang cukup panjang yaitu sekitar 4 abad (1644 s.d. 1912 M), yaitu abad 17 - 20 (Eriawati, 2010: 7).

Selanjutnya berdasarkan analisis diketahui bahwa fragmen keramik yang ditemukan terdiri atas piring, mangkuk, sendok makan, botol, buli-buli, cangkir kecil untuk minuman beralkohol. Keramik dari dinasti ini pada umumnya dibuat oleh seniman dengan dekorasi yang diambil dari lingkungan alam sekitarnya, antara lain manusia, binatang, air terjun, pemandangan alam, atau desain tekstil seperti brokat dan bordir kuno. Motif-motif tersebut dibuat dalam dua warna yaitu biru dan putih. Piring biru dan putih dengan dasar ganda dari periode dinasti ini banyak ditemukan di Indonesia. Selain itu terdapat keramik lain (masih dari Dinasti Qing) yang banyak ditemukan di Indonesia adalah buatan dari pusat keramik di Yixing dekat Shanghai (Provinsi Jiangxu) dan yang ada di dekat Guangzhou (Provinsi Guangdong). Keramik dari dua provinsi ini pada umumnya dalam bentuk batuan merah (Adhyatman, 1990: $69-70$ ).

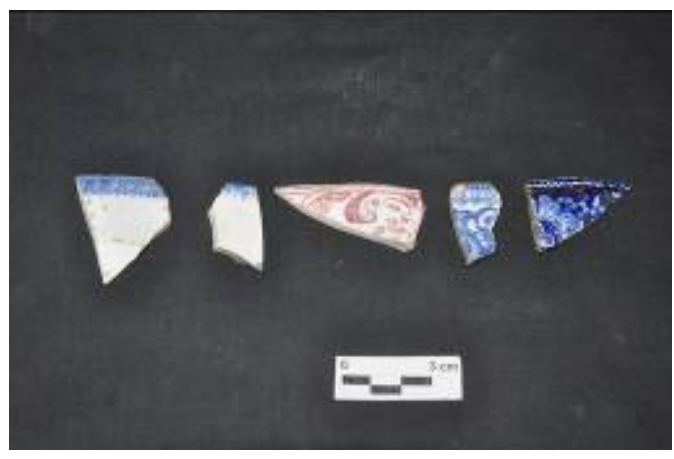

Gambar 17. Foto beberapa contoh keramik asing

Sumber: Balai Arkeologi D.I. Yogyakarta

Urutan berikutnya adalah fragmen kaca yang berjumlah 65 fragmen. Diketahui bahwa fragmen 
tersebut menunjukkan bentuk wadah yang terdiri atas botol dan gelas. Khusus untuk botol terdapat dua bentuk yaitu botol dengan penampang persegi (bujur sangkar) dan botol dengan penampang bulat. Kedua jenis botol tersebut dibuat dalam beberapa warna yaitu hijau tua, hijau muda, putih, putih kebirubiruan (biru muda), dan putih kekuning-kuningan (kuning muda). Warna dominan pada fragmen kaca yang ditemukan adalah warna hijau muda dan hijau tua. Warna untuk wadah yang berupa gelas adalah transparan. Temuan yang demikian ini mirip dengan yang ada di Kota Lama Semarang. Dalam penelitian di kawasan tersebut banyak sekali ditemukan fragmen kaca. Pada umumnya fragmen kaca yang ditemukan merupakan bentuk wadah dengan mayoritas berupa botol yang berdasar bulat dan persegi dengan leher panjang atau pendek. Sementara dari variasi warna adalah putih transparan, hijau daun, hijau terang, dan coklat tua (Abbas, 2013: 32).

Urutan selanjutnya adalah temuan fragmen tulang sebanyak 56. Berdasarkan atas analisis temuan diketahui bahwa terdapat 2 jenis hewan yaitu bovidae dan gallus $s p$ (ayam). Dari kedua jenis hewan tersebut mayoritas temuan merupakan fragmen tulang bovidae. Melihat jenis tulang yang ditemukan kemungkinan bahwa kedua jenis hewan tersebut yang sering dikonsumsi para penghuni Benteng Van den Bosch pada waktu itu.

Terakhir temuan fragmen kerang sejumlah 1 dan ditemukan di kotak P1. Kotak P1 terletak di bagian depan benteng yaitu pada bagian parit. Kerang sebagai binatang air dan di Benteng Van den Bosch ditemukan pada parit atau kolam. Dapat diketahui bahwa kerang (mollusca) ini secara fisik berbentuk oval (lonjong) terdiri atas dua yang ditelangkupkan menjadi satu (bivalvia). Jenis ini banyak ditemukan dalam siput darat (Dharma, 1992: 36 dan 88). Dengan jenis yang demikian ini sesuai antara jenis temuan dengan lokasi ditemukannya mollusca tersebut.

Selanjutnya terdapat temuan yang berupa unsur bangunan yang terdiri atas fragmen genteng, gorong-gorong air, dan temuan tegel. Khusus untuk temuan goronggorong atau bis beton secara kronologis dapat diperkirakan keberadaannya pasca Benteng Van den Bosch. Lebih khusus lagi keberadaan gorong-gorong atau bis beton ini setelah jembatan angkat tidak berfungsi lagi. Dengan tidak berfungsinya jembatan angkat, maka parit yang ada di bawah jembatan angkat diurug dengan tanah. Selanjutnya agar parit yang ada di kanan dan kiri bekas jembatan angkat airnya dapat dialirkan maka dipasanglah gorong-gorong yang terbuat dari bis beton.

\section{PENUTUP}

Pada bagian akhir ini akan diuraikan berdasarkan dua hal, yaitu kesimpulan dan rekomendasi, yaitu:

\section{Kesimpulan}

\section{a. Survei}

Hasil survei menunjukkan bahwa Benteng Van den Bosch di Ngawi dan lingkungannya merupakan tinggalan masa lalu yang penting. Benteng ini tidak berdiri sendiri, tetapi menyatu dengan tinggalan monumental yang berupa bangunan rumah tinggal, kompleks makam, dan bangunan tempat bersenang-senang. 


\section{b. Ekskavasi}

Secara umum temuan fragmen gerabah yang ada merupakan gerabah polos ditambah sedikit yang berhias. Terdapat dua kelompok yaitu wadah dan nonwadah. Jenis kendil, pengaron, kuali, genuk, padasan, kelenting, jun, kekep, kendi, gentong, keren, dan mangkuk merupakan kelompok wadah. Sedangkan figurin, gacuk, alat upam (?) atau gacuk besar, dan manik-manik merupakan kelompok non-wadah. Sementara itu terdapat 3 fragmen gerabah berhias yaitu motif sisik ikan pada fragmen genuk; motif kelopak mata pada fragmen padasan; dan motif rantai pada fragmen pengaron. Temuan logam terdiri atas beberapa jenis, yaitu paku, mur-baut, fragmen besi, fragmen lempeng, pengait, fragmen kawat berduri, selongsong peluru, peniti dan kancing, fragmen engsel pintu, fragmen slot pintu, fragmen jeruji, tutup kaleng, dan kunci, mata uang, timang ikat pinggang, emblem, peniti, dan kancing, serta ring. Temuan paku, mur-baut, dan fragmen besi terlihat sangat dominan. Temuan fragmen keramik asing berasal dari Eropa (Belanda?) dan Cina. Khusus untuk fragmen keramik Eropa diketahui karena adanya tulisan "MADE IN HOLLAND". Sementara fragmen keramik Cina pada umumnya berasal dari Dinasti Qing tahun 1644 s.d. 1912 M atau abad 17 - 20. Berdasarkan bentuknya fragmen keramik asing tersebut berupa piring, mangkuk, sendok makan, botol, buli-buli, dan cangkir kecil. Temuan fragmen kaca berupa wadah yang terdiri atas botol dan gelas. Khusus temuan botol dengan penampang persegi dan bulat. Botol tersebut dibuat dalam beberapa warna yaitu hijau tua, hijau muda, putih, putih kebiru-biruan (biru muda), dan putih kekuning-kuningan (kuning muda) dengan dominasi warna hijau muda dan hijau tua. Sedangkan warna untuk gelas adalah transparan. Temuan tulang binatang merupakan hewan bovidae dan gallus sp (ayam) dengan mayoritas berupa fragmen tulang bovidae. Dimungkinkan bahwa kedua jenis hewan tersebut yang sering dikonsumsi para penghuni Benteng Van den Bosch pada waktu itu. Data yang berupa fragmen kerang (mollusca) ditemukan di kotak yang terletak di parit atau kolam. Jenis yang demikian ini ditemukan pada siput darat dan sesuai dengan lokasi ditemukannya mollusca tersebut.

Selanjutnya terdapat temuan yang berupa unsur bangunan yang terdiri atas fragmen genteng, gorong-gorong air, dan temuan tegel. Khusus untuk temuan goronggorong secara kronologis dapat diperkirakan keberadaannya pasca Benteng Van den Bosch. Lebih khusus lagi keberadaan goronggorong ini setelah jembatan angkat tidak berfungsi lagi. Dengan tidak berfungsinya jembatan angkat, maka parit yang ada di bawah jembatan angkat diurug dengan tanah. Selanjutnya agar parit yang ada di kanan dan kiri bekas jembatan angkat airnya dapat dialirkan maka dipasanglah gorong-gorong yang terbuat dari bis beton. Sementara tegel yang ada di benteng ini dibuat oleh pabrik porselin dan gerabah yang terletak di kota Maastricht (Belanda) dan berproduksi pada sekitar tahun 1835.

\section{Rekomendasi}

Mencermati objek yang berkaitan erat dengan temuan yang bersifat monumental perlu dilakukan berbagai upaya. Salah satu upaya nyata yaitu berkaitan dengan masa 
depan objeknya. Hal ini penting sebab objek tersebut secara nyata merupakan benda cagar budaya yang dilindungi oleh Undang-undang Republik Indonesia No. 11 Tahun 2010 tentang Cagar Budaya (CB). Terkait dengan hal itu terdapat beberapa rekomendasi yaitu:

a. Benteng Van den Bosch perlu dilestarikan sebagai monumen cagar budaya dan perlu penataan lingkungan atau kawasan agar dapat dimanfaatkan untuk berbagai kepentingan.

b. Perlu adanya tim yang bertugas untuk menyusun kegiatan dan prosedur agar situs beserta objeknya segera ditetapkan sebagai cagar budaya. Selain itu juga melakukan kegiatan tindak lanjut guna memutuskan apakah bangunan Benteng Van den Bosch akan "dibangun kembali" seperti bentuk semula, atau dibiarkan seperti keadaan sekarang namun dikonservasi agar objek tetap aman dan lestari untuk dimanfaatkan.

c. Pemerintah Daerah Kabupaten Ngawi bersama pemangku kepentingan dapat menyusun dan menyiapkan dokumen perencanaan pengelolaan kawasan seperti Rencana Tata Bangunan dan Lingkungan (RTBL) dan Rancangan Induk (masterplan) Pengelolaan Benteng Van den Bosch.

\section{UCAPAN TERIMAKASIH}

Ucapan terimakasih ini ditujukan kepada pihak-pihak yang telah membantu dalam penelitian Benteng Pendem Tahun 2013. Untuk itu sudah sewajarnya apabila pada kesempatan ini penulis memberikan ucapan terimakasih kepada seluruh anggota tim penelitian dari Balai Arkeologi Yogyakarta; Balai Pelestarian Cagar Budaya Provinsi Jawa Timur; Jurusan Arkeologi, Fakultas IImu Budaya, Universitas Gadjah Mada; dan Pemerintah Daerah Kabupaten Ngawi (Dinas Pariwisata, Kebudayaan, Pemuda, dan Olah Raga) yang tergabung dalam tim Penelitian Benteng Van den Bosch Di Kabupaten Ngawi, Provinsi Jawa Timur. Hal yang sama ditujukan pula kepada Bataliyon ARMED 12 KOSTRAD Ngawi; Desa Pelem, Kecamatan Ngawi; serta seluruh masyarakat di sekitar lokasi penelitian. 


\section{DAFTAR PUSTAKA}

Anonim. Undang-undang Republik Indonesia Nomor 11 Tahun 2010 tentang Cagar Budaya (CB).

Abbas, Novida. 1996/1997. "Laporan Hasil Penelitian Arkeologi Survei Sarana Pertahanan Kolonial Di Kabupaten Ngawi, Kabupaten Bangkalan, Kabupaten Situbondo, Provinsi Jawa Timur (Tahap IV)", Laporan Penelitian Arkeologi. Yogyakarta: Balai Arkeologi.

2001. "Dutch Forts of Jawa, A Locational Study", Master Thesis. Singapore: National University of Singapore.

---------. 2013. "Laporan Penelitian Arkeologi Identifikasi Potensi Dan Pengelolaan Sumberdaya Arkeologi Di Kawasan Kota Lama Semarang (Tahap VI) Laporan Penelitian Arkeologi. Yogyakarta: Balai Arkeologi.

Adhyatman, Sumarah. 1990. Antique Ceramics Found in Indonesia, Various Uses and Origins. Jakarta: Jayakarta Agung Offset. Cetakan Kedua.

Anonim. 1989. Ensiklopedi Nasional Indonesia (Buku 5). Jakarta: PT. Cipta Adi Pustaka.

Dharma, Benjamin. 1992. Indonesian Shells II: Siput dan Kerang Indonesia. Grillparzerstr-Wiesbaden: Verlag Christa Hemmen.

Eriawati, Yusmaini. 2010. "Keramik", (Materi kursus). Yogyakarta: Balai Arkeologi.

Sumarno, Aris. 1990. "Benteng Pendem Belanda Abad XIX Di Kabupaten Ngawi, Tinjauan Terhadap Arsitektur dan Pemilihan Lokasi". Skripsi Sarjana, Yogyakarta: Jurusan Arkeologi, Fakultas Sastra, Universitas Gadjah Mada.

Sumijati As. 1998. "Manfaat Kajian Gerabah Masa Lalu Bagi Pengembangan Kerajinan Tembikar Sebagai Penunjang Industri Pariwisata", Berkala Arkeologi Tahun XVIII Edisi No. 2 / November 1998. Yogyakarta: Balai Arkeologi.

https://nl.wikipedia.org/wiki/Maastrichts_aardewerk 